\title{
Investigating Lecturers' Perceptions of the Performance of Computer-Based and Paper Pencils-Based for Assessing Sports Training Program during COVID-19
}

\author{
Achmad Sofyan Hanif ${ }^{1, *}$, Syeni Ratna Amelia ${ }^{1}$, Fatah Nurdin ${ }^{1}$, Hernawan $^{1}$, Uzizatun Maslikah ${ }^{1}$, \\ Meirizal Usra ${ }^{2}$, Ruslan Abdul Gani ${ }^{3}$, Edi Setiawan ${ }^{4}$, Hasanuddin Jumareng ${ }^{5}$ \\ ${ }^{1}$ Faculty of Sport Science, Universitas Negeri Jakarta, Indonesia \\ ${ }^{2}$ Department of Physical Education Health and Recreation, Universitas Sriwijaya, Indonesia \\ ${ }^{3}$ Department of Physical Education Health and Recreation, Universitas Singaperbangsa Karawang, Indonesia \\ ${ }^{4}$ Department of Physical Education Health and Recreation, Universitas Suryakancana, Indonesia \\ ${ }^{5}$ Department of Physical Education Health and Recreation, Universitas Halu Oleo, Indonesia
}

Received June 17, 2021; Revised July 26, 2021; Accepted August 27, 2021

\begin{abstract}
Cite This Paper in the following Citation Styles
(a): [1] Achmad Sofyan Hanif, Syeni Ratna Amelia, Fatah Nurdin, Hernawan, Uzizatun Maslikah, Meirizal Usra, Ruslan Abdul Gani, Edi Setiawan, Hasanuddin Jumareng , "Investigating Lecturers' Perceptions of the Performance of Computer-Based and Paper Pencils-Based for Assessing Sports Training Program during COVID-19," International Journal of Human Movement and Sports Sciences, Vol. 9, No. 5, pp. 1004 - 1010, 2021. DOI: 10.13189/saj.2021.090522.

(b): Achmad Sofyan Hanif, Syeni Ratna Amelia, Fatah Nurdin, Hernawan, Uzizatun Maslikah, Meirizal Usra, Ruslan Abdul Gani, Edi Setiawan, Hasanuddin Jumareng (2021). Investigating Lecturers' Perceptions of the Performance of Computer-Based and Paper Pencils-Based for Assessing Sports Training Program during COVID-19. International Journal of Human Movement and Sports Sciences, 9(5), 1004 - 1010. DOI: 10.13189/saj.2021.090522.
\end{abstract}

Copyright $\odot 2021$ by authors, all rights reserved. Authors agree that this article remains permanently open access under the terms of the Creative Commons Attribution License 4.0 International License

Abstract The lack of information regarding exercise program assessment tools during the COVID-19 pandemic was the main gap in this research. The purpose of this study was to investigate lecturers' perceptions of computer-based and paper pencil-based performance to assess sports training programs during the COVID-19 pandemic. In this study, a combination of quantitative and qualitative (mixed) is used as a method. Participants in this study were male and female lecturers from Jakarta State University $(\mathrm{N}=15)$ and Sriwijaya University $(\mathrm{N}=10)$. Quantitative instruments use questionnaires and qualitative instruments use in-depth interviews with participants. Quantitative data analysis use the IBM SPSS version 25.0 to find descriptive data, namely mean, standard deviation and percentage of responses from participation. Meanwhile, qualitative data analysis use qualitative thematic data. The results of the study based on quantitative data found that the majority of lecturers strongly agreed to use computer-based instead of paper pencil-based to assess sports training programs. Meanwhile, research results based on qualitative data show that most lecturers favour computer-based over paper pencil-based during the COVID-19 pandemic. Thus, computer-based has better performance and advantages than paper pencil-based when used in the pandemic era. This research provides benefits for the development of science assessment tools in the field of sports.

Keywords Lecturer's Perception, Computer-Based, Paper Pencil-Based, COVID-19

\section{Introduction}

During the COVID-19 pandemic, the use of technology in learning, training or sports activities is increasing rapidly [1]. The technology is used as a support so that these activities can be carried out optimally [2], [3]. The technology that is often used is a computer which one of its functions is to assess or evaluate products, applications or training programs created by students [4], [5]. However, the assessment and evaluation of exercise programs in the field of sports is still paper pencil-based and this assessment is claimed by several researchers to have significant effects and have a high level of accuracy for 
assessing a work [6]. But in the COVID-19 era paper pencil-based is difficult to implement, because paper and pencil-based allow spreading of the virus among students and lecturers massive. One way to overcome this problem is by using a computer-based [7].

Despite many benefits that have been found by previous studies on computer-based, some researchers confuse the benefit and performance of computer-based compare to paper pencil-based [8]. The next gap found that there was not difference significantly between performance paper pencil-based and computer-based on learning outcomes assessment [9]. Similar results are reported by Akdemir \& Oguz [10], showing that there is no difference in performance between computer-based and paper pencil-based. With a gap in the previous study, this research offers further research about computer-based performance versus paper pencil-based in the context of sports, so that the research later will provide scientific insight about which assessment system is more effective in the COVID-19 era.

Despite a lot of research on computer-based [11], [12], [13], [14], [15]. However, no previous research that has reported about lecturers' perceptions on the performance of computer-based and paper pencil-based in the COVID-19 era. In addition, previous studies about computer-based were carried out in general education and there is still little literature on computer-based in the context of sports. This research offers a different research from previous research, namely using a mixed-method so that the results of the research can be obtained through quantitative and qualitative data.

The urgency of this research problem is the importance of computer-based and paper pencil-based facts as a tool for assessing and evaluating sports training programs during the current COVID-19 pandemic, so that the findings from this research analysis can provide information for lecturers, trainers, teachers and practitioners about advantages and disadvantages of computer-based and paper and pencil-based. This research is expected to be a solution to reveal about effective assessment tools to be used during the COVID-19 pandemic. This study aims to determine lecturers' perceptions of computer-based and paper and pencil-based performance to assess sport training programs during the COVID-19 pandemic.

\section{Literature Review}

\subsection{Lecturer's Perception of Computer-Based and Paper Pencil-Based}

Lecturers' perceptions of computer-based and paper pencil-based are very important to investigate, because later the results of this study will provide information about the good or bad performance of computer-based to assess an exercise program created by students.
Computer-based is an assessment system that is carried out by using technology assistance such as computers [16], [7], laptops connected to the internet network [17]. Computer-based function to assist lecturers in carrying out assessment activities on students learning outcomes without having to direct meeting a person in the campus area [18]. Computer-based is able to present attractive features, because it can be accompanied by multimedia, graphics, short video clips [19], or sound files. Computer-based can provide feedback and is equipped with scoring facilities that can be accessed by students online. The other superiority of computer-based is that it can assess students' learning outcomes in a relatively great quantities [20]. The results of previous research found that computer-based has the power to increase motivation in conducting evaluations for students [21]. Quantitively of superiority the computer-based then the popularity of computer based has continued to increase significantly and has been used at school to university level in several countries [17], [22], [12], [23].

While paper pencil-based is a traditional assessment using paper and pencil to provide an assessment of the exercise program made by students. Previous studies reported that the use of pencil-based paper could reduce costs, can avoid data entry errors [24].

Given the previous literature that shows the advantages of computer-based and paper pencil-based, it is important to examine more deeply about these two assessment tools.

\section{Materials and Methods}

\subsection{Methods}

The mixed-method (qualitative and quantitative), in this research is used as a methodological approach [14]. Some experts define mixed-methods as a methodology that combines qualitative and quantitative as a way to solve problems [25], [26]. According to Creswell [27], mixed-methods research is a study that combines quantitative and qualitative research. Thus, mixed research will produce facts that are more comprehensive in researching research problems.

\subsection{Participation}

Participants in this research came from two universities in different regions in Indonesia with details of male and female lecturers $(\mathrm{N}=15)$ from the State University of Jakarta. Then, male and female lecturers $(\mathrm{N}=10)$ from the University of Sriwijaya. The sampling technique used to determine the participants was purposive sampling by selecting lecturers who were experts in the assessment system. Before the research began, all participants in this research were asked to sign a letter regarding their willingness to sample in all activities. To protect the sample identity the authors gave code P. For more details, 
the characteristics of the subject can be seen in Table 1 .

Table 1. The Characteristics of Participants

\begin{tabular}{ccc}
\hline $\begin{array}{c}\text { Age } \\
(\text { year })\end{array}$ & $\begin{array}{c}\text { Height } \\
(\mathbf{c m})\end{array}$ & $\begin{array}{c}\text { Weight } \\
(\mathbf{k g})\end{array}$ \\
\hline $31.2 \pm 1.12$ & $159.7 \pm 1.74$ & $57.70 \pm 2.99$ \\
\hline
\end{tabular}

The value can be presented as mean \pm standard deviation.

\subsection{Instruments}

To measure of lecturers perceptions about computer-based and paper pencil-based, can use a questionnaire as an instrument for quantitative research [28], as follows:

Q1: I prefer to carry out the assessment using computer-based.

Q2: I prefer to carry out the assessment using paper pencil-based.

Q3: Computer-based is more effective in the COVID-19 era.

Q4: Paper pencil-based is easier to implement instead of computer-based.

Q5: Computer-based is more objective for assessment in learning outcomes.

The above questionnaire has been tested especially until it has a validity level of .98 and a reliability of .81 . Testing the validity and reliability using IBM SPSS version 25.0. To complete the questionnaire above, it can be using a Likert scale from 1 (strongly disagree) to 5 (strongly agree).

Then, this research using in-depth interviews with respondents as a qualitative instrument [14]. The questions asked are:

Question 1: What makes computer-based more superior to paper and pencil for assessing learning outcomes in the COVID-19 era?

Question 2: Which assessment do you prefer between computer-based and paper pencil-based?

Question 3: Which assessment is more objective?

\subsection{Research Procedure}

This research has received permission from the State University of Jakarta and the University of Sriwijaya with Circular 21/04/2021. In addition, this research has followed the Ethics guidelines from the World Medical Association (Helsinki Declaration). In the first phase of the research (e.g. the first week) all participants were instructed to fill out a questionnaire that had been provided on the computer online with a duration of 60 minutes. Then in the second phase of the research (e.g. a second week) all participants were instructed to complete a paper pencil-based questionnaire with a duration of 60 minutes. All participants were interviewed individually for 10-30 minutes. Interviews were conducted in the Indonesian language. In-depth interviews were carried out via whatapps telephone.

\subsection{Data Collection Technique}

Collecting data in this study is through two steps: first through filling out a questionnaire. A questionnaire is a technique for collecting data when carrying out quantitative research by giving written questions to participants. The questionnaire is a data collection technique that is efficient and effective in obtaining answers from relatively many participants. Second through interviews with the research participant. According to Creswell [27], interviewing is a technique for collecting data by conducting questions and answers between researchers and participants. Interviews can be conducted through face to face or can use technological media, such as Whatsapp, Webex, Zoom meetings, Google meet, Telegram. Interviews are an effective way to collect qualitative data.

\subsection{Data Analysis Technique}

Characteristic of data quantitative will be analyzed by using IBM SPSS application version 25, which functions to test the statistical descriptive (mean, standard deviation) and percentage. Meanwhile, the analysis processed after the research data qualitative from the interviews have been collected, including: (1) Interviews are transcribed word by word. (2) The transcribed interviews is read repeatedly by the author to get a broad understanding. (3) The texts are arranged based on a description of the experience and then each given label. (4) Data are sorted based on categorization, coding, and highlighting based on similarities. (5) A collection of similar phrases grouped and arranged into the initial theme. (6) Examining the meanings of the phenomenon being studied. (7) Arranging the data into themes with a description of each theme. (8). Share themes with parents to get a deeper understanding [29].

\section{Result}

The results of this quantitative study found that lecturers' perceptions of computer-based and paper pencil-based on the Q1 indicator showed high results $(4.60 \pm 0.50)$ with the percentage of strongly agree $60 \%$, agree $40 \%$, neutral $0 \%$, disagree $0 \%$, strongly disagree $0 \%$. The Q2 indicator scores $(4.80 \pm 0.41)$ with the percentage of strongly agree $0 \%$, agree $0 \%$, neutral $20 \%$, disagree $0 \%$, strongly disagree $80 \%$. Then for the Q3 indicator $(4.04 \pm 0.79)$ with the percentage of strongly agree $32 \%$, agree $40 \%$, neutral $28 \%$, disagree $0 \%$, strongly disagree $0 \%$. While the Q4 indicator scored $(4.92 \pm 0.28)$ with a percentage of strongly agree $0 \%$, agree $8 \%$, neutral $92 \%$, disagree $0 \%$, strongly disagree $0 \%$. While the Q5 indicator scored $(4.80 \pm 0.41)$ with a percentage of strongly agree $80 \%$, agree $20 \%$, neutral $0 \%$, disagree $0 \%$, strongly disagree $0 \%$ (Table 2). 
Table 2. Lecturers' perceptions of computer-based and paper pencil-based

\begin{tabular}{|c|c|c|c|c|c|c|}
\hline Item & Strongly agree & Agree & Neutral & Disagree & Strongly Disagree & M(SD) \\
\hline Q1 & $\begin{array}{c}15 \\
(60 \%) \\
\end{array}$ & $\begin{array}{c}10 \\
(40 \%) \\
\end{array}$ & $\begin{array}{c}0 \\
(0 \%) \\
\end{array}$ & $\begin{array}{c}0 \\
(0 \%) \\
\end{array}$ & $\begin{array}{c}0 \\
(0 \%) \\
\end{array}$ & $4.60 \pm(0.50)$ \\
\hline Q2 & $\begin{array}{c}0 \\
(0 \%) \\
\end{array}$ & $\begin{array}{c}0 \\
(0 \%) \\
\end{array}$ & $\begin{array}{c}5 \\
(20 \%) \\
\end{array}$ & $\begin{array}{c}0 \\
(0 \%) \\
\end{array}$ & $\begin{array}{c}20 \\
(80 \%) \\
\end{array}$ & $4.80 \pm(0.41)$ \\
\hline Q3 & $\begin{array}{c}8 \\
(32 \%) \\
\end{array}$ & $\begin{array}{c}10 \\
(40 \%)\end{array}$ & $\begin{array}{c}7 \\
(28 \%) \\
\end{array}$ & $\begin{array}{c}0 \\
(0 \%) \\
\end{array}$ & $\begin{array}{c}0 \\
(0 \%)\end{array}$ & $4.04 \pm(0.79)$ \\
\hline Q4 & $\begin{array}{c}0 \\
(0 \%)\end{array}$ & $\begin{array}{c}2 \\
(8 \%)\end{array}$ & $\begin{array}{c}23 \\
(92 \%) \\
\end{array}$ & $\begin{array}{c}0 \\
(0 \%) \\
\end{array}$ & $\begin{array}{c}0 \\
(0 \%) \\
\end{array}$ & $4.92 \pm(0.28)$ \\
\hline Q5 & $\begin{array}{c}20 \\
(80 \%) \\
\end{array}$ & $\begin{array}{c}5 \\
(20 \%) \\
\end{array}$ & $\begin{array}{c}0 \\
(0 \%) \\
\end{array}$ & $\begin{array}{c}0 \\
(0 \%) \\
\end{array}$ & $\begin{array}{c}0 \\
(0 \%) \\
\end{array}$ & $4.80 \pm(0.41)$ \\
\hline
\end{tabular}

What follows is a selected overview of some of the key responses to our questions. The qualitative research results are presented as follows:

\section{Theme 1: Excellence}

Question 1: What makes computer-based more superior to paper pencil-based for assessing learning outcomes in the COVID-19 era?

Participants expressed their positive perceptions of computer-based compared to paper pencil-based [28]. For example, see some of the common quotation selected by participants as follows:

"Computer-based is more excellent than paper pencil-based in the COVID-19 era, because of computer-based can be done anytime and anywhere, by preparing a computer, laptops or handphone that connected to an adequate internet network we can carry out an assessment on learning outcomes that students create (e.g., creating learning support programs or applications) )” P1, P3, P5, P7, P10.

"Computer-based is a technology that is effectively used in the era of COVID-19 to assess student product results, because computer-based can provide feedback (e.g., provide scores, corrections or suggestions) directly to the work, ideas or products produced by students" P4, P6, P8, P9, P11, P12.

Another participant gave his opinion:

"Computer-based provides immediate feedback with answers and explanations. In addition, students can find out about the advantages and disadvantages of the products they create" P2, P13, P14.

Some participants argue that:

"Computer-based is more excellent than paper pencil-based, because it can assess or evaluate a relatively large number of products made by students. This means that computer-based has a better level of efficiency than paper pencil-based" P15, P16, P21, $\mathrm{P} 24$.

"Although paper pencil-based has several evaluation models (e.g., CIIP), the use of these models will not be very effective and optimal in the era of COVID-19 to evaluate a product." P17, P18, P19, P20, P22, P23.

"The difference in performance between computer-based and paper pencil-based can be seen from the time difference in completing an assessment of the work, product, or program created by students. Using computer-based we were able to complete the assessment in about 40-50 minutes while the paper and pencil took about 1 hour. Another advantage of computer-based is that it is very easy to access and has interesting features." P25.

\section{Theme 2: Most Preferred Assessment}

Question 2: Which assessment do you prefer between computer-based and paper pencil-based?

About the assessment system the participants gave his opinion that:

"We prefer to use computer-based in the current pandemic era, because computer-based makes it easy for us to assess and evaluate products created by students. Through computer-based we can provide scores, corrections and suggestions directly through the computer-based platform and students can find out." P1, P2, P4, P5, P7, P9, P10.

Some of the participants expressed the opinion:

"We prefer computer-based, because the use of computer-based in pandemic conditions will be safer than paper pencil-based. In addition, lecturers can assess and evaluate student products in a relatively large number. ” P3, P8, P11, P13, P15, P16.

"We favor computer-based over paper pencil-based, because computer-based has the advantage of being able to conduct assessments anywhere, anytime and without any time limit. Simply by logging on to the computer-based platform, we can assess students' work." P6, P12, P14.

The other participants argued:

"The use of paper pencil-based in the COVID-19 era will experience obstacles and be difficult to implement, because there are so many regulations issued by the Indonesian government, for example social or physical distancing or not being allowed to hold activities with 
a large number of people. With this regulation, we think it will be difficult to implement paper pencil-based in current conditions," P17, P18, P19, P20, P21.

"We prefer to use computer-based, because computer-based is easy to access, attractive, more efficient and effective. In addition, with computer-based we can clearly see the works presented by students. Computer-based is an assessment method we will always use during the COVID-19 pandemic." $\mathrm{P} 22, \mathrm{P} 23$, $\mathrm{P} 24, \mathrm{P} 25$.

\section{Theme 3: Objective}

Question 3: Which assessment is more objective?

Participants expressed the opinion that:

"We think that computer-based is much more objective to conduct and provide an assessment of the products created by students. Computer-based can provide an assessment without face to face between lecturers and students, thereby minimizing the occurrence of subjective assessments." $\mathrm{P} 1, \mathrm{P} 12$, P3, P14, P5, P6, P7, P8, P9, P10, P11, P22, P20, P24, $\mathrm{P} 25$.

"Computer-based is more objective than paper pencil-based, because the assessment is carried out through a platform with different user names and passwords between lecturers and students, so that the results of the assessment cannot be known by others." P2, P13, P4, P15, P16, P17, P18, P19, P23, P21.

\section{Discussions}

The purpose of this study is to investigate lecturers' perceptions of computer-based and paper pencil-based performance to assess sport training programs during the COVID-19 pandemic. The quantitative research results show that there is a significant difference the performance of computer-based and paper pencil-based. The findings in this study are not in line with previous studies which reported that there was no significant difference between performance on computer-based and paper pencil-based [9]. In addition, the research conducted by Khoshsima \& Toroujeni [14] also confirms that based on the results of show that there was not difference value by significant statistically between paper pencil-based and computer-based. The results are not in line between this study and previous research due to several factors, namely the first is the very different conditions of computer-based and paper pencil-based implementation, where in the previous study a study was conducted on the performance of computer-based and paper pencil-based under normal conditions in Indonesia, absence of the COVID-19 pandemic [30], whereas this study examines computer-based and paper pencil-based in pandemic conditions, so this factor is the answer to why there is a difference in performance between computer-based and paper pencil-based. Second, because of the different characteristics of computer-based and paper pencil-based, computer-based prioritizes the use of technology and internet assistance [31], [32], while paper pencil-based is more dominant in using pencil and paper assistance [33] as well as direct observation of the product to be assessed [34]. If you look at the current conditions, the computer-based assessment system is more profitable because it has many advantages, for example computer-based can be done anytime and anywhere [35]. In addition, it can provide direct assessments and evaluations in the form of notes or videos [36]. Then computer-based has a high level of accuracy and objectivity to assess a product [37]. In addition, according to Garas \& Hassan [38], computer-based can increase efficiency and provide instantaneous feedback to students, which is more fun and not boring for students. In contrast to the paper pencil-based which is difficult to do in the current pandemic and tends to pose a big risk, for example, being unable to conduct an assessment with a relatively large number of students. Lecturers are not objective when giving assessments, because they are anxious and afraid of contracting COVID-19. Thus, these factors cause the difference in performance between computer-based and paper pencil-based.

Meanwhile, based on the qualitative results most of the participants thought that computer-based had special quality (e.g. it was easier to implement, could be assess learning outcomes with a large number of students, received feedback instantly, could know directly the exam score) [39], [28] compared to paper and pencil to assess students' learning outcomes in sport or assess sports training programs during the COVID-19 era. The results of this research were also supported by previous studies which reported that most participants showed preference of computer-based that a higher than paper and pencil and also more excellent of computer-based to compare of paper pencil-based [40]. The results of research conducted by Jeong [41], support the results of this study, the data reports that there is a significant difference between computer-based and paper pencil-based performance to assess Korean learning outcomes.

\section{Conclusions}

Based on the results of quantitative data, this research confirms that the majority of lecturers answered "strongly agree" to use computer-based to assess sports training programs during the pandemic. In addition, the qualitative 
data collected from the interview sessions shows that most of the lecturers chose and favored computer-based over paper pencil-based to assess and evaluate all the work of students in field sport during the COVID-19 era.

The implication of this research is to add to the literature on computer-based and paper pencil-based, so that later it can provide scientific insights to lecturers about the implementation of assessment and evaluation of sports traning program made by students during the COVID-19 era. Further research needs to be done, for example comparing the computer-based assessments system with other assessments such as google classroom versus zoom meeting.

\section{Acknowledgements}

Our gratitude goes to the samples who contributed to this research and we also thank the State University of Jakarta and University of Sriwijaya who have provided support to carry out this research.

\section{REFERENCES}

[1] H. Jumareng, E. Setiawan, I. A. Patah, M. Aryani, A. Asmuddin, and R. A. Gani, "Online Learning and Platforms Favored in Physical Education Class during COVID-19 Era: Exploring Student' Perceptions," Int. J. Hum. Mov. Sport. Sci., vol. 9, no. 1, pp. 11-18, 2021.

[2] Ambiyar, M. L. Hamzah, A. A. Purwati, and E. Saputra, "Computer based test using tcexam as an instrument learning evaluation," Int. J. Sci. Technol. Res., vol. 8, no. 9, pp. 1066-1069, 2019.

[3] S. A. Nikou and A. A. Economides, "The impact of paper-based, computer-based and mobile-based self-assessment on students' science motivation and achievement," Comput. Human Behav., vol. 55, pp. 12411248, 2016.

[4] Z. Geraili-Afra, A. Abadi, J. Yazdani-Charati, S. A. Gooraji, M. Zarghami, and S. Saadat, "The effect of computer-based tests on nursing students' test anxiety: A quasi-experimental study," Acta Inform. Medica, vol. 26, no. 2, pp. 115-118, 2018.

[5] J. Yang and Z. Zhao, "Development and implementation of computer assisted instruction system in physical education based on ASP.NET Technology," Int. J. Emerg. Technol. Learn., vol. 14, no. 13, pp. 145-156, 2019.

[6] S. Kirschner, A. Borowski, H. E. Fischer, J. Gess-Newsome, and C. von Aufschnaiter, "Developing and evaluating a paper-and-pencil test to assess components of physics teachers' pedagogical content knowledge," Int. J. Sci. Educ., vol. 38 , no. 8, pp. 1343-1372, 2016.

[7] E. Istiyono, W. S. B. Dwandaru, R. Setiawan, and I. Megawati, "Developing of computerized adaptive testing to measure physics higher order thinking skills of senior high school students and its feasibility of use," Eur. J. Educ. Res., vol. 9, no. 1, pp. 91-101, 2020.

[8] M. Ajinaja, "The Design and Implementation of a Computer Based Testing System Using Component-Based Software Engineering," J. Appl. Comput., vol. 8, no. 1, pp. 58-65, 2017.

[9] M. Hosseini, M. J. Z. Abidin, and M. Baghdarnia, "Comparability of Test Results of Computer based Tests (CBT) and Paper and Pencil Tests (PPT) among English Language Learners in Iran," Procedia - Soc. Behav. Sci., vol. 98, pp. 659-667, 2014.

[10] O. Akdemir and A. Oguz, "Computer-based testing: An alternative for the assessment of Turkish undergraduate students," Comput. Educ., vol. 51, no. 3, pp. 1198-1204, 2008 .

[11] M. Jawaid, F. A. Moosa, F. Jaleel, and J. Ashraf, "Computer based assessment (CBA): Perception of residents at Dow University of Health Sciences," Pakistan J. Med. Sci., vol. 30, no. $4,2014$.

[12] R. A. Nugroho, N. S. Kusumawati, and O. C. Ambarwati, "Students Perception on the Use of Computer Based Test," IOP Conf. Ser. Mater. Sci. Eng., vol. 306, no. 1, 2018.

[13] S. Bandele and O.A.Olatunji, "The Attitude Of Students To General Studies Computer Based Tests In Universities In South West Nigeria," Int. J. Interdiscip. Res. Methods, vol. 6, no. 2, pp. 23-34, 2019.

[14] H. Khoshsima and S. M. H. Toroujeni, "Computer-based testing: Score equivalence and testing administration mode preference in a comparative evaluation study," Int. J. Emerg. Technol. Learn., vol. 12, no. 10, pp. 35-55, 2017.

[15] L. A. Schindler, G. J. Burkholder, O. A. Morad, and C. Marsh, "Computer-based technology and student engagement: a critical review of the literature," Int. J. Educ. Technol. High. Educ., vol. 14, no. 1, 2017.

[16] R. M. Jamil, Tariq, and P. Shami, "Computer-Based Vs Paper-Based Examinations: Perceptions Of University Teachers," Turkish Online J. Educ. Technol., vol. 11, no. 4, pp. 371-381, 2012.

[17] H. Jati, R. D. Ristanto, and Nurkhamid, "Implementation of CBT (Computer-Based Test) System on Aptitude Test Development Using C4.5 Algorithm as Potential Detection Tool for Choosing High School Major," J. Phys. Conf. Ser., vol. 1413, no. $1,2019$.

[18] C. Flowers, D. Kim, P. Lewis, and V. C. Davis, "A Comparison of Computer-based Testing and Pencil-andPaper Testing for Students with a Read-aloud Accommodation," J. Spec. Educ. Technol., vol. 26, no. 1, pp. 1-12, 2011.

[19] A. J. Boevé, R. R. Meijer, C. J. Albers, Y. Beetsma, and R. J. Bosker, "Introducing computer-based testing in high-stakes exams in higher education: Results of a field experiment," PLoS One, vol. 10, no. 12, 2015.

[20] S. L. Wise, "Controlling construct-irrelevant factors through computer-based testing: disengagement, anxiety, \& cheating," Educ. Inq., vol. 10, no. 1, pp. 21-33, 2019.

[21] M. Hariri-Akbari, B. Shokrvash, F. Mahmoodi, F. Jahanjoo-Aminabad, B. Yousefi, and F. Azabdaftari, 
"Conversion of extrinsic into intrinsic motivation and computer based testing (CBT)," BMC Med. Educ., vol. 18, no. 1, pp. 1-8, 2018.

[22] C. Y. Piaw, "Replacing Paper-based Testing with Computer-based Testing in Assessment: Are we Doing Wrong?," Procedia - Soc. Behav. Sci., vol. 64, pp. 655-664, 2012.

[23] K. Shraim, "Online examination practices in higher education institutions: Learners' perspectives," Turkish Online J. Distance Educ., vol. 20, no. 4, pp. 185-196, 2019.

[24] E. Colasante et al., "Paper-and-pencil versus computerized administration mode: Comparison of data quality and risk behavior prevalence estimates in the European school Survey Project on Alcohol and other Drugs (ESPAD)," PLoS One, vol. 14, no. 11, pp. 1-13, 2019.

[25] A. Baim-Lance, A. J. Onwuegbuzie, and J. P. Wisdom, "Project management principles for optimizing publication productivity of mixed methods studies," Qual. Rep., vol. 25, no. 3, pp. 646-661, 2020.

[26] J. A. Corrigan and A. J. Onwuegbuzie, "Toward a meta-framework for conducting mixed methods representation analyses to optimize meta-inferences," Qual. Rep., vol. 25, no. 3, pp. 785-812, 2020.

[27] Creswell W. John, Research Design Pendekatan Kualitatif, Kuantitatif, dan Mixed. Yogyakarta: Pustaka Pelajar, 2013.

[28] A. Helfaya, "Assessing the use of computer-based assessment-feedback in teaching digital accountants," Account. Educ., vol. 28, no. 1, pp. 69-99, 2019.

[29] Rasmitadila et al., "The perceptions of primary school teachers of online learning during the covid-19 pandemic period: A case study in Indonesia," J. Ethn. Cult. Stud., vol. 7, no. 2, pp. 90-109, 2020.

[30] Y. Karay, S. K. Schauber, C. Stosch, and K. Schüttpelz-Brauns, "Computer Versus Paper-Does It Make Any Difference in Test Performance?," Teach. Learn. Med., vol. 27, no. 1, pp. 57-62, 2015.

[31] S. M. Al-Saleem and H. Ullah, "Security Considerations and Recommendations in Computer-Based Testing," Sci. World J., vol. 2014, 2014.
[32] O. T. Oluwatosin and D. D. Samson, "Computer-Based Test: Security and Result Integrity," Int. J. Comput. Inf. Technol., vol. 02, no. 02, pp. 2279-764, 2013.

[33] M. Al-Qdah and I. Ababneh, "Comparing Online and Paper Exams: Performances and Perceptions of Saudi Students," Int. J. Inf. Educ. Technol., vol. 7, no. 2, pp. 106-109, 2017.

[34] T. M. Fagbola, A. A. Adigun, and A. O. Oke, "Computer-Based Test (Cbt) System For University Academic Enterprise Examination," Int. J. Sci. Technol. Res., vol. 2, no. 8, pp. 336-342, 2013.

[35] Handoko, B. Tolla, and Y. Suprihatin, "The evaluation of computer-based national examination system in Indonesia," Indones. J. Educ. Rev., vol. 6, no. 1, pp. 35-43, 2019.

[36] S. Daryazadeh and A. Faghihi, "Experiences of Medical Students About Computer-based Testing: A Qualitative Study," Educ. Res. Med. Sci., vol. 9, no. 2, 2021.

[37] Y. Karay, S. K. Schauber, C. Stosch, and K. Schuettpelz-Brauns, "Can computer-based assessment enhance the acceptance of formative multiple choice exams? A utility analysis," Med. Teach., vol. 34, no. 4, pp. 292-296, 2012.

[38] S. Garas and M. Hassan, "Student performance on computer-based tests versus paper-based tests in introductory financial accounting: UAE evidence," Acad. Account. Financ. Stud. J., vol. 22, no. 2, pp. 1-14, 2018.

[39] I. Glogger, L. Holzäpfel, J. Kappich, R. Schwonke, M. Nückles, and A. Renk1, "Development and Evaluation of a Computer-Based Learning Environment for Teachers: Assessment of Learning Strategies in Learning Journals," Educ. Res. Int., no. January, pp. 1-12, 2013.

[40] M. R. Ebrahimi, S. M. H. Toroujeni, and V. Shahbazi, "Score equivalence, gender difference, and testing mode preference in a comparative study between computer- based testing and paper-based testing," Int. J. Emerg. Technol. Learn., vol. 14, no. 7, pp. 128-143, 2019.

[41] H. Jeong, "A comparative study of scores on computer-based tests and paper-based tests," Behav. Inf. Technol., vol. 33, no. 4, pp. 410-422, 2014. 